\title{
An Overview of Chassis Dynamometer in the Testing of Vehicle Emission
}

\author{
Zhuo Yang ${ }^{1}$, Baoqing Deng ${ }^{1, \mathrm{a}}$ Mengqi Deng ${ }^{2}$ and Shaojia Huang ${ }^{1}$ \\ ${ }^{1}$ Department of Mechanical and Automotive engineering, Zhuhai College of Jilin University, Zhuhai, China \\ ${ }^{2}$ School of Automotive Studies, Tongji University, Shanghai, China
}

\begin{abstract}
Air pollution is a risk to health and the vehicle emission is becoming a serious cause of the air pollution. Vehicle emission is influenced by many factors. The measurement of the vehicle emission can be achieved by the chassis dynamometer which can simulate the driving on the real road. The chassisdynamometer-based testing can provide a repeatable experiment and precise emission evaluation under various driving condition. In this paper, we review the testing of vehicle emission based on a chassis dynamometer. The investigation results manifest that advance testing method for achieving the real-world driving resistance should be studied and better data analysis method should be proposed to get a more reasonable driving cycle.
\end{abstract}

\section{Introduction}

Vehicle emission depends on many factors such as vehicle characteristics, traffic situation, driving style, emission control technology, fuel specification and ambient and operation condition $[1,2]$. Such emission factors decide the relation between the driven distance and the quantity of the pollutant emitted during the interval. Also, the emission factors reflect the recent advance of the vehicle technology and the development of emission control, which also manifests the direction of vehicle development. The emission measurement techniques have a broad category ranging from the large road simulation system (chassis dynamometer) to portable emission measurement device.

A chassis dynamometer is a device that can simulate the resistance imposed to the wheel of a vehicle according to different driving cycles (Figure1). During the testing, the vehicle is tied and running on loading controllable rollers keeping a stationary state. According to the predefined time-velocity curve shown on a monitor, the driver operates the vehicle to match the curve in different driving cycles. Then the exhaust gas will be output to an online exhaust gas analyzer for emission measurement. Moreover, it can be tested in a range of different temperature according to the testing requirement.

The purpose of the chassis dynamometer testing for vehicle emission lies in three aspects which are analyzing the emission of a specific vehicle, assessing the emission control performance and testing the emission of different types of fuels, respectively. This paper aims to provide different testing methods for vehicle emission with the help of the chassis dynamometer listing the advantage and disadvantage of such a measurement

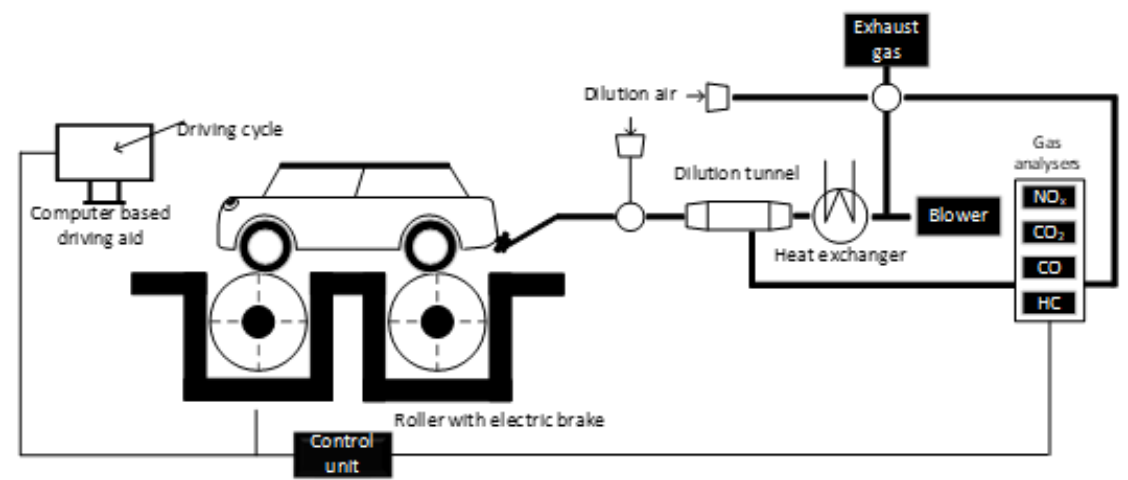

Figure 1 The block diagram of chassis dynamometer system for vehicle emission testing [2]. 


\section{The applications of chassis dynamometer for vehicle emission}

\author{
2.1. Emission testing for different types of \\ vehicle
}

\subsubsection{Passenger vehicle}

Chiang et al. used the chassis dynamometer to compare the emission of passenger vehicles which included new vehicles, in-use vehicles and highly polluting vehicles [3]. The US federal procedure (FTP-75) was adopted as the driving cycle for their experiment. Their experiments validated that the deterioration of the exhaust catalysts increased the pollution while the tune-up (change the lubrication oil, air filter and spark plug) for the high polluted vehicle had less effect in reducing the emission of pollutant. Also, the pollutant for a new and in-use car which produced during cold start account for more than $50 \%$ under the testing with FTP-75. This result manifest that to form a habit of warming up the car in subtropical areas can reduce the pollutant efficiently.

\subsubsection{Light duty vehicle}

Light-duty vehicles are always tested on a chassis dynamometer to obtain vehicle emission for different driving cycles [4]. However, due to the complexity of realworld traffic, the emission test on dynamometer cannot precisely match the emission performance on real-world traffic, and only a reasonable driving cycle could reflect an actual emission. For example, the New European Drive Cycle (NEDC) is too smooth to indicate a vehicle emission. Pelkmans and Debal used two kinds of light-duty vehicles to compare the emission between real-world traffic and on chassis dynamometer testing [5]. In their testing, the emission of the NEDC cycle was compared with a realtraffic based cycle (MOL cycle) on a chassis dynamometer. The emission of NOx for MOL cycle was more than ten times higher than that with NEDC cycle due to the frequent low speed /high torque operation. Their results manifest that a more realistic driving cycle with more acceleration should be adopted to assess the emission of a vehicle. Otherwise, the manufacturers can confine the engine operating zones to get low emission of a vehicle [6]

Huai et al. estimated the emission rate of nitrous oxide using different driving cycle with light-duty vehicles. Before this study, researchers mainly focused on some primary studies on $\mathrm{N}_{2} \mathrm{O}$ emission such as fundamental catalyst reaction, analyzing the emission rates of $\mathrm{N}_{2} \mathrm{O}$ from vehicles and the mechanism of forming $\mathrm{N}_{2} \mathrm{O}$ under the environment of catalyst [7-9]. However, Huai et al. estimated the $\mathrm{N}_{2} \mathrm{O}$ emission of a modern vehicle equipped with advanced emission control system on a chassis dynamometer, which helped to predict the future development of $\mathrm{N}_{2} \mathrm{O}$ emission control system. They used 60 light-duty vehicles which ranged from non-catalyst vehicles to super-low-emission vehicles to run on different driving cycles (FTP, US06, cold start ST01, etc.). Their results showed that $\mathrm{N}_{2} \mathrm{O}$ emission formed at the beginning of catalyst light-off and decreased with the increase of the temperature of catalyst until to the equilibrium temperature. Also, the cold start accounts for a large proportion of $\mathrm{N}_{2} \mathrm{O}$ emission.

\subsubsection{Hybrid electric vehicle}

The hybrid electric vehicle has the potential to reduce the emission of a pollutant, and the primary emission of the hybrid electric vehicle lies in the transport-generated $\mathrm{CO}_{2}$ emission [10]. Therefore, the evaluation of greenhouse gas emission became urgent for optimizing the hybrid electric vehicle design. Fontaras et al. evaluated the emission of two hybrid electric vehicles (2005 Toyota PriusII and 2003 Honda Civic IMA) on a chassis dynamometer with both NEDC (UDC (cold and hot), EUDC and NEDC) and realworld simulation driving cycles (Artem Urban, Artem Road, and Artem Motorway). As mentioned before, the real-world simulation driving cycle can avoid underestimating of vehicle emission which is conducted with NEDC cycle. The results showed that the emission levels of Civic were higher than that of Prius in most driving cycle especially in urban driving conditions because of the higher hybridization level of PriusII. They also compared the emission of the two hybrid electric vehicles with diesel Euro3, gasoline Euro3 and gasoline Euro4 vehicles under the Artemis strategy. The results manifest that the hybrid electric vehicles have improved vehicle emission than conventional cars and the hybrid electric vehicles are more suitable to the urban driving condition.

\subsubsection{Heavy-duty vehicle}

A heavy-duty vehicle contributes more atmospheric oxides of nitrogen $\left(\mathrm{NO}_{\mathrm{x}}\right)$ than a light-duty vehicle [11] However, the emission testing with chassis dynamometer is not commonly used for the heavy-duty vehicle because of the cost of the device as well as the cost of testing. Zhen et al. developed a heavy heavy-duty diesel engine schedule for the measurement of vehicle emission [12]. In this testing, seven heavy heavy-duty trucks which had three weights were tested on heavy-duty vehicle chassis dynamometer which four modes (creep, transient, cruise and high-speed cruise). Such four modes can represent driving conditions of urban travel and freeway operation. For each mode, there was a time/velocity curve and such curves were separated into four microtrips. For two different modes, the lengths of the corresponding microtrips are different. For example, the first microtrip for creep mode was different from that for the transient mode. With more experimental data added, a mode database was generated. Then a candidate mode was created by using a different combination of all available microtrips in the database. After that, the best candidate mode was made with least square error method which was shown in Figure2. Such a best candidate mode can represent the mode database, the test weight, different engine manufacturers and the real-world performance of heavy-duty vehicles [12]. 


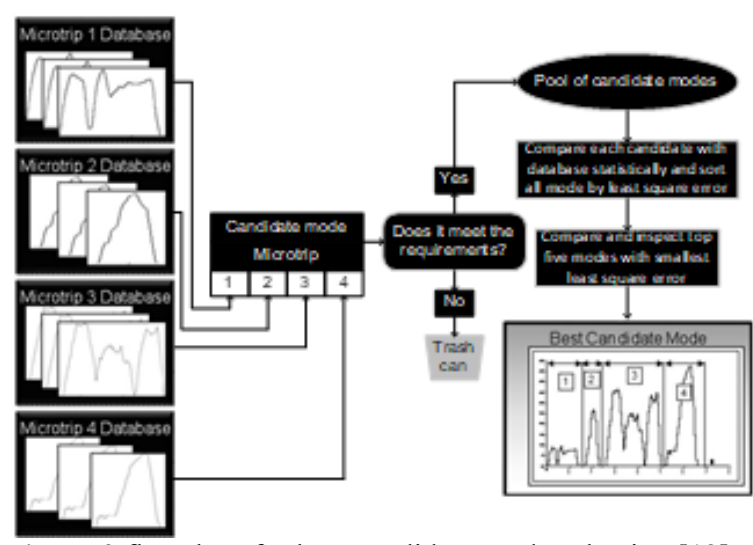

Figure 2 flowchart for best candidate mode selection [12].

\subsection{Evaluation of emission control technology}

The chassis dynamometer can also be used for the evaluation of emission control technology. Biswas et al. used the chassis dynamometer to investigates the oxidative potential (OP) of PM from vehicles with six retrofitted technologies ranging from the vanadium and zeolite-based selective catalytic reduction to uncatalyzed Horizon filter [13]. Four heavy-duty vehicles were adopted in this study. In the setting of the chassis dynamometer, one of the four vehicles were not equipped with any post engine emission technology, and each of other three vehicles was tested with three of the six after-treatment devices. The consumption rate of dithiothreitol (DDT) measured the OP for the PM samples collected at ambient and elevated temperatures. There was a significant reduction in OP $(60 \%$ to $98 \%$ ) with the control devices. Also, correlation analysis was conducted between all species, and OP was strongly associated with water-soluble organic carbon (WSOC) $(\mathrm{R}=0.94)$ and organic acids $(\mathrm{R}=0.91)$. the most important observation of the study lay in the significant reduction in OP with the denudation of the aerosols from their semivolatile fraction which manifested that particle OP generally stems from the semivolatile PM fractions

\subsection{Testing the vehicle emission of different types of fuel}

To resolve the energy crisis and environmental problem, scientists are trying to apply different kinds of fuel on different vehicles and the chassis dynamometer can be a useful tool for the precise measurement of emissions for such vehicles. For example, Dardiotis et al. [14] tested two flex-fuel vehicles' emission which was equipped with various ethanol blends (E5, E75, E85). The tests were performed at $22 \mathrm{C}$ and $-7 \mathrm{C}$ under both legislative (cold start NEDC) and non-legislative (hot start Common Artemis Driving Cycle) real-world driving cycles. The results showed that the $\mathrm{CO}$ emission decreased in all conditions with $\mathrm{E} 85$ at $22 \mathrm{C}$. At $-7 \mathrm{C}$, both the $\mathrm{CO}$ and $\mathrm{HC}$ emission increased with the high content ethanol fuel (E75). Such a result was in line with the emission behavior and fuel consumption of the ethanol vehicle in Europe which can benefit the study of environmental impact of the flex-fuel vehicle.

\subsection{Assessing the influence of the driving style on vehicle emission and fuel consumption}

Driving styles also influence the vehicle emission. Mierlo et al. developed a measurement campaign to study the influence of driving styles on vehicle emissions [1]. They evaluated three driving style tips (shift as soon as possible at a maximum of $2500 \mathrm{r} / \mathrm{min}$ to as high a gear as possible; press the throttle quickly and vigorously as much as it takes to keep up with the traffic; do not shift down to a lower gear too early and keep the car rolling without disengaging the clutch and in as high a gear as possible). The test-driver was asked to drive on the road according to the driving style tips. After that, the on-road measured cycles were transformed to representative speed profiles for the vehicle emission testing on chassis dynamometers. The results showed that a reduction of fuel consumption from $5 \%$ to $25 \%$ could be achieved by changing the driving styles. Moreover, the CO emission reduced 59\% following tip1 and tip3 in extra-urban driving cycles for a petrol engine.

\section{Advantage and disadvantage of the chassis dynamometer testing}

The chassis dynamometer provides a repeatable way for the emission testing, and the test is relatively fast and cost saving compared with the on-road testing. By testing the influence of changed driving behavior on a chassis dynamometer, engineers can optimize the road design and traffic management for a fluent and environmentally friendly driving style [1]. Also, the testing on chassis dynamometer is a standard process with a high accuracy which can benefit the comparison of performance between different vehicles. Another advantage lies in the experiment with chassis dynamometer can involve the factor of climate into the experiment regardless of ambient temperature [14]. However, the chassis dynamometer testing also has drawbacks. The most important disadvantage is that such a testing cannot reflect the realworld driving conditions and real-world vehicle emission. The driving condition varies each time while driving on the road, and with the development of the city and improvement of living standard, it is hard to guarantee such a circumstance can relief the traffic congestion. Also, the driving resistance exerted to a vehicle on the chassis dynamometer is derived from the vehicle coast-down test under different conditions which cannot precisely reflect the resistance on the real-world road [2].

\section{Conclusion}

In this paper, we introduce different applications of chassis dynamometer for vehicle emission in four aspects which are emission testing of different types of vehicle, evaluation of emission control technology, testing vehicle emission of different types of fuel, and assessing the influence of the driving style on vehicle emission and fuel consumption. We also give out the advantage and disadvantage according to the applications. The chassis dynamometer is an efficient way for the testing of vehicle 
emission. We also believe that the advance testing method for real-world driving resistance should be investigated, and a better data analysis method should be studied for developing reasonable driving cycle, which can benefit the precise measurement of vehicle emission with the testing on a chassis dynamometer.

\section{Acknowledgement}

This project is supported by Premier-Discipline Enhancement Scheme Supported by Zhuhai Government Fund (2015YXXK14).

\section{Reference}

1. J. Van Mierlo, G. Maggetto, E. Van de Burgwal, and R. Gense, "Driving style and traffic measuresinfluence on vehicle emissions and fuel consumption," Proc. Inst. Mech. Eng. Pt. D: J. Automobile Eng., vol. 218, pp. 43-50, (2004).

2. V. Franco, M. Kousoulidou, M. Muntean, L. Ntziachristos, S. Hausberger, and P. Dilara, "Road vehicle emission factors development: A review," Atmos. Environ., vol. 70, pp. 84-97, (2013).

3. H. L. Chiang, J. H. Tsai, Y. C. Yao, and W. Y. Ho, "Deterioration of gasoline vehicle emissions and effectiveness of tune-up for high-polluted vehicles," Transp. Res. D: Transp. Environ., vol. 13, pp. 47-53, (2008).

4. T. Huai, T. D. Durbin, J. W. Miller, and J. M. Norbeck, "Estimates of the emission rates of nitrous oxide from light-duty vehicles using different chassis dynamometer test cycles," Atmos. Environ., vol. 38, pp. 6621-6629, (2004).

5. L. Pelkmans and P. Debal, "Comparison of on-road emissions with emissions measured on chassis dynamometer test cycles," Transp. Res. D: Transp. Environ., vol. 11, pp. 233-241, (2006).

6. L. Ntziachristos and Z. Samaras, "Speed-dependent representative emission factors for catalyst passenger cars and influencing parameters," Atmos. Environ., vol. 34, pp. 4611-4619, (2000)

7. H. Hirano, T. Yamada, K. Tanaka, J. Siera, P. Cobden, and B. Nieuwenhuys, "Mechanisms of the various nitric oxide reduction reactions on a platinumrhodium (100) alloy single crystal surface," Surf. Sci., vol. 262, pp. 97-112, (1992).

8. N. W. Cant, D. E. Angove, and D. C. Chambers, "Nitrous oxide formation during the reaction of simulated exhaust streams over rhodium, platinum and palladium catalysts," Appl. Catal., B, vol. 17, pp. 63-73, (1998).

9. E. Jobson, G. Smedler, P. Malmberg, H. Bernler, O. Hjortsberg, I. Gottberg, et al., "Nitrous oxide formation over three-way catalyst," SAE Technical Paper 0148-7191, 1994.

10. C. S. N. Shiau, N. Kaushal, C. T. Hendrickson, S. B. Peterson, J. F. Whitacre, and J. J. Michalek, "Optimal plug-in hybrid electric vehicle design and allocation for minimum life cycle cost, petroleum consumption, and greenhouse gas emissions," J. Mech. Design, vol. 132, p. 091013, (2010).

11. R. Ramamurthy and N. N. Clark, "Atmospheric emissions inventory data for heavy-duty vehicles," Environ. Sci. Technol., vol. 33, pp. 55-62, (1999).

12. F. Zhen, N. N. Clark, C. R. Bedick, M. Gautam, W. S. Wayne, G. J. Thompson, et al., "Development of a heavy heavy-duty diesel engine schedule for representative measurement of emissions," J. Air Waste Manage. Assoc., vol. 59, pp. 950-959, (2009).

13. S. Biswas, V. Verma, J. J. Schauer, F. R. Cassee, A. K. Cho, and C. Sioutas, "Oxidative potential of semivolatile and non volatile particulate matter (PM) from heavy-duty vehicles retrofitted with emission control technologies," Environ. Sci. Technol., vol. 43, pp. 3905-3912, (2009).

14. C. Dardiotis, G. Fontaras, A. Marotta, G. Martini, and U. Manfredi, "Emissions of modern light duty ethanol flex-fuel vehicles over different operating and environmental conditions," Fuel, vol. 140, pp. 531540, (2015). 